\title{
A novel integrative approach to improve the quality of life by reducing pain and kinesiophobia in patients undergoing TKA: the IARA Model
}

\author{
Anna Maria Padovan ${ }^{1,2}$ \\ Gianmosé Oprandi ${ }^{3}$ \\ Johnny Padulo ${ }^{1,4,5}$ \\ Claudia Bruno ${ }^{3}$ \\ Michela Isoardi ${ }^{3}$ \\ Francesca Gulotta ${ }^{2}$ \\ Goran Kuvačić4,5 \\ Andrea De Giorgio ${ }^{1,4,5}$ \\ 1 eCampus University, Faculty of Psychology, \\ Novedrate (CO), Italy \\ 2 Kiara Association, Torino, Italy \\ ${ }^{3}$ City of Bra Clinic, Bra, Italy \\ ${ }^{4}$ University of Split, Faculty of Kinesiology, \\ Split, Croatia \\ ${ }^{5}$ University of Split, Sport Performance Laboratory, \\ Split, Croatia
}

Corresponding author:

Andrea De Giorgio

Faculty of Psychology,

eCampus University

Via Isimbardi 10

22060 Novedrate (CO), Italy

E-mail: andrea.degiorgio@uniecampus.it

\section{Summary}

Introduction: Postoperative complications in TKA are well-known, especially regarding kinesiophobia which affects both perception of pain and good post-operation recovery, preventing the normal course and sometimes leading to a new intervention even in the presence of a technically successful operation.

Methods: The study had a quasi-experimental, controlled, before-and-after design and was conducted on 84 patients; 44 were assigned to IARA and $\mathbf{4 0}$ to control group. According to IARA model three meetings were performed (two pre- and one postoperative). The control group received normal preand postoperative interaction. With the purpose of evaluating pain, kinesiophobia and health-related Quality of Life (QoL), we used respectively the NRS $0-10, T S K$, and KOOS questionnaires.

Results: Applying two-way mixed design ANOVA we found significant Time $\times$ Group interaction in all KOOS subscales: Pain $\left(F_{1,82}=10.808, p<0.001\right)$; Symptom $\left(F_{1,82}=15.497, p<0.001\right)$; ADL $\left(F_{1,82}=20.342\right.$, $p<0.001)$; Sport/Rec $\left(F_{1,82}=20.451, p<0.001\right)$; $Q O L$ $\left(F_{1,82}=4.275, p<0.001\right)$ and also in TSK questionnaire $\left(F_{1,82}=4.275, p=0.042\right)$.

Conclusion: IARA turned out to be a short and effective approach to reducing kinesiophobia and pain at $40^{\text {th }}$ day after surgery, significantly improving QoL indexes in patient undergoing TKA.

Level of evidence: III.

KEY WORDS: knee, empowerment, education, guided imagery, fear of movement.

\section{Introduction}

Problems deriving from total knee arthroplasty (TKA), a surgical technique that significantly improves the quality of life $(\mathrm{Q} o \mathrm{~L})^{1}$ are generally present even when studies show that there are high rates of surgical success $^{2}$. Indeed, it is known how post-surgical pain can affect the quality of life in subjects who have received a perfectly successful surgical intervention ${ }^{3}$.

Pain, on the other hand, is the aspect that most of all leads to TKA intervention and what may trigger a new operation. Therefore, pain management can be considered one of the most important challenges for TKA success ${ }^{3}$.

The persistence of pain after TKA has been studied by many researchers taking into account many aspects such as age, sex, body weight ${ }^{4}$. However, psychological factors are becoming one of the key to pain management ${ }^{5}$, demonstrating that the perception and interpretation of pain by the individual is decisive ${ }^{5}$.

Furthermore, concerning the role of cognitive, emotional and behavioural aspects in chronic pain and disability it has been proposed the so-called fearavoidance model, which explains how pain induces an impaired self-esteem leading to a strong fear of movement, said kinesiophobia 6 .

Kinesiophobia can be described as an avoidance of physical activity induced by fear of pain in the $a b-$ sence, in the case of TKA, of valid post-surgical reasons. Kinesiophobia induces a vicious circle of fearpain-avoidance that increases the perception of their disability and leads to disuse syndrome ${ }^{7}$. A proper management of perioperative pain and kinesiophobia is essential in treating orthopaedic surgery patients ${ }^{3}$. The reduction of fear of movement, which is aforementioned, is closely related to pain ${ }^{5}$, can lead to significant effect on outcomes ${ }^{8}$. However, other psychological and emotional aspects are in close relation- 
ship to pain and modulate each other in both directions also influencing the care process ${ }^{8,9}$.

Martin et al. ${ }^{10}$ discussed as patients need to have the opportunity to tell the story of their unique illness experiences and, knowing them as a person, allows the health professional to understand decisive elements in order to achieve the patient's adherence such as psychological factors, social support, cultural context, beliefs, subjective norms, attitudes, and emotional health challenges (anxiety, depression, distress).

Literature has also shown how the collaboration process between the various health figures is decisive for the patient's well-being and how this process leads the patient to be the protagonist of his/her care pathway ${ }^{11}$.

Accompanying the person in his/her perioperative path is therefore decisive in making him/her more serene and aware, as it is decisive that the various health professionals interact so as to keep the person in the middle on his/her path by implementing personalized assistance ${ }^{11}$.

The influence of kinesiophobia in TKA has been already studied, demonstrating a correlation with the post-surgery recovery time and over its impact on the final outcome ${ }^{3}$, but many researches do not check any changes between pre- and postoperative, a problem previously discussed by Bourne et al. ${ }^{12}$.

Here we want to present a new and systematic approach to accompanying the surgical patient by evaluating its effectiveness throughout the entire perioperative course on pain, kinesiophobia and quality of life: the IARA Model. IARA was already used in diseases with a strong psychogenic component ${ }^{13-19}$. This model is based on: I) Assagioli psychosynthesis $^{16}$ and counseling principles ${ }^{17}$; II) patient-centered concept care ${ }^{11}$; III) guided imagery effectiveness ${ }^{18,19}$; IV) empowerment education ${ }^{20,21}$. IARA was structured into three meetings in which patients received educational intervention on both their knee illness and movements to be performed before and after surgery; guided imagery intervention; all information in regard to the perioperative period. The aim of this study was to verify whether IARA could be a useful method to decrease kinesiophobia and pain, improving the quality of life in patients undergoing TKA.

\section{Materials and methods}

\section{Subjects}

Between March 2016 and May 2017, 100 patients admitted for planned primary TKA were enrolled in the investigation from specialist orthopaedic outpatient clinics in northern Italy. This study had a quasi-experimental, controlled, before-and-after design. The surgical procedure was carried out under the National Health Service. The intervention group (IARA group) was consecutively recruited between $30^{\text {th }}$ October 2016 and $1^{\text {st }}$ May 2017 and 44 patients were finally analyzed $(\mathrm{M}=11 ; \mathrm{F}=33)$ with an average age of 70.69 years $(S D=7.61)$ with two preoperative meetings and the postoperative meeting according to the IARA method.

The control group was consecutively recruited between $1^{\text {st }}$ March 2016 and $1^{\text {st }}$ July 2016 and 40 patients were finally analyzed $(M=19 ; F=21)$, with an average age of 72.24 years $(S D=11.01)$.

Both groups completed the questionnaires before and after surgery.

Patients were included if they were scheduled for TKA (following an accurate medical examination which took into account several factors such as mechanical pain in knee region lasting for more than six months; pain refractory to medical therapy, etc.), willing to participate, and able to complete the questionnaires. Exclusion criteria were not Italian speaking, knee arthroplasty following fractures, revision surgery and partial replacement, patients with concomitant neurologic, rheumatologic (rheumatoid arthritis), cognitive impairment, and neoplasia (further information in the study flow chart; Fig. 1).

\section{Procedures}

Surgery procedure and anaesthetic given pre- and postoperative

Access to the joint was front (mid-vastus). A tourniquet was applied to the thigh $<90$ minutes with Tranex protocol for homeostasis control. The prosthesis was cemented PS (rear stabilization, LCP sacrifice). Cemented kneecap prosthesis. Furthermore, physiotherapy was made from the $2^{\text {nd }}$ post-surgery day until four weeks. Spinal anaesthesia was established with 1 vial $2 \mathrm{ml}$ hyperbaric bupivacaine $1 \%$ (Marcaine ${ }^{\circledR}$ Spinal Heavy) + 25 mcg fentanyl (Fentanest $\left.{ }^{\circledR}\right)$. In the immediate postoperative were administered iv paracetamol $1000 \mathrm{mg}$ (1 vial, Perfalgan ${ }^{\circledR}$, Bristol-Myers Squibb) and iv $1 / 2$ vial $(5 \mathrm{mg})$ of morphine.

During the first $24 \mathrm{~h}$ were administered: ketorolac tromethamine (2 vials $30 \mathrm{mg}$ each, Toradol ${ }^{\circledR}$, Recordati) + iv tramadol hydrochloride (2 vials $50 \mathrm{mg}$ each, Contramal ${ }^{\circledR}$, Grünenthal) + iv metoclopramide $10 \mathrm{mg}$ (1 vial, Plasil ${ }^{\circledR}$, Sanofi) in $0.9 \% \mathrm{NaCl} 500 \mathrm{ml}$ to infuse at $30 \mathrm{ml} / \mathrm{h}$.

At 8 and 16 hours after surgery was administered iv paracetamol $1000 \mathrm{mg}$ and iv 1 vial of morphine in need. Starting 24 hours after the intervention were administered paracetamol $1000 \mathrm{mg} 3$ times per day and 5 or $10 \mathrm{mg} 2$ times per day of oxycodone and naloxone (Targin ${ }^{\circledR}$, Mundipharma). Finally, diclofenac $75 \mathrm{mg}$ (Voltaren ${ }^{\circledR}$, Novartis) was available if needed.

\section{Standard procedure (Control group)}

During the preoperative orthopaedic examination (15 days before surgery) the physician explains the patient the strictly technical phases, or rather he shows the patient's imaging surveys explaining his/her knee problems, summarizes the function of the knee, shows the prosthesis and briefly explains. Successively, the patient is invited to see a brochure explaining the preoperative muscle training exercises. After the orthopaedic visit the patient fill out the KOOS 
Patients enrolled in IARA group

$$
\mathrm{n}=\mathbf{5 0}
$$

30th October 2016 -1st May 2017

$$
\text { | }
$$

Excluded following a pre-assessment visit at a local hospital

$$
\mathrm{n}=\mathbf{2}
$$

Excluded because failed to fill out questionnaires

$$
\mathrm{n}=\mathbf{4}
$$

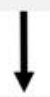

$$
\begin{gathered}
\text { Data analyzed } \\
\text { IARA group } \\
\mathrm{n}=\mathbf{4 4}
\end{gathered}
$$

Patients enrolled in Control group

$$
\mathrm{n}=\mathbf{5 0}
$$

1st March 2016 - 1st July 2016

Excluded following a pre-assessment visit at a local hospital

$$
\mathrm{n}=\mathbf{4}
$$

Excluded because

failed to fill out questionnaires

$$
\begin{gathered}
n=6 \\
\downarrow
\end{gathered}
$$

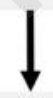

$$
\begin{gathered}
\text { Data analyzed } \\
\text { Control group } \\
\mathrm{n}=\mathbf{4 0}
\end{gathered}
$$

Figure 1. The diagram represents flowchart of the study with patients enrolled/excluded by investigation.

questionnaire and hand it over to the physician. On the preoperative day patient fill out the TSK questionnaire. On the day of the operation at $8 \mathrm{pm}$, the first assessment of pain perception was performed according to NRS $0-10$. The morning after the operation (8 am) the NRS 0-10 was checked again. At 40 days after surgery, or shortly after the first specialist postoperative outpatient visit, patient completed the KOOS and TSK questionnaire again.

\section{Intervention (IARA group)}

First IARA meeting: fifteen days before surgery The first meeting takes place 15 days before the surgery and after the last specialist preoperative visit by a nurse with Master's Degree in Psychology who has learned and used the IARA model. Physician who visits the patient provides the nurse valuable information about patient medical history. Patients in the intervention group fill out the KOOS questionnaire after the orthopaedic visit and hand it over to the IARA operator. The one-hour meeting begins with the patient's knowledge of the operation he/she will undergo. In addition to the information the person claims to have received, there is much scope for the patients to describe how he/she feels about the operation and how feelings and fears are imagined. The operator leaves the narration free.

Then the patient is asked to draw how he/she feels the affected part of the symptom at this time and then the subject is invited to observe his/her drawing and describe the meaning. In doing so, the patient is invited to express the manner in which he would eliminate the symptom, then graphically illustrate how the same healed part is imagined.

A further drawing is required about the anatomical knowledge of the area to be operated. Now that the operator has a clear picture of the patient's awareness of the patient's pathway, provides the missing information to improve the anatomical knowledge and the entire care itinerary, including surgical procedures.

Then, the patient is invited to write seven qualities that he/she thinks he/she owns and to choose two of them to use during the course of the treatment. If the caregiver is present, he/she is also asked to write seven qualities and to choose two of them to be made available to the relative to accompany him/her in the surgical process. Patients are invited to enrich this list during the preoperative period.

The IARA operator will then demonstrate musclestrengthening exercises to do during the previous days by asking the patient to try them on this occasion so as to test their actual awareness (e.g. correct muscle recruitment). Operator encourages patient to perform the exercises at home.

Finally, the operator makes the patient try the crutch- 
es inviting him/her to try exactly what kind of use he will have to do in the postoperative period and explains the entire organizational procedure (e.g., material to bring into the clinic and any personal objects in order to personalize the days of stay, treatment paths, perioperative interaction).

Before leaving the patient, he/she is informed about the possibility of preparing a playlist to be heard in the headphone before and during the surgery.

Second IARA meeting: seven day before surgery The second meeting takes place 7 days before the operation. This one-hour encounter starts with the patient's free narrative about the days spent between the two meetings. The patient is also called upon to resolve any doubt about the perioperative period. Operator describes again the entire perioperative procedure, also describing the health figures that step by step will meet on the day of surgery and will take care of patient. The entire anaesthesiological procedure (including effects of drugs used) is also described. At this point, the patient (and the caregiver if present) is re-invited to reflect on their qualities, also asking if he/she has enriched the list during the days between the meetings.

The operator asks the patient if he/she would use the same qualities as the first meeting for his/her care path or if he/she would choose another two (the same thing is required for the caregiver).

It is also proposed, during this meeting, the exercise of guided imagery, through which the operator "makes living" the operation to the patient (Box 1). The patient is also taught to use the little men in a targeted postoperative post to accompany the various wound healing and the prosthesis stabilization processes (Box 2). The muscle strengthening exercises and the use of the crutches are also checked and the correct execution is carried out. The operator still encourages patient to perform the exercises at home. Then he/she is asked if he/she has prepared a musical playlist and is so dismissed.

Day before and day after surgery

The day before the operation, all patients fill out the TSK questionnaire and only those in the IARA model have a brief meeting with the nurse who followed the preparation. On the day of the operation at $8 \mathrm{pm}$, the first assessment of pain perception was performed according to NRS $0-10$.

The morning after the operation (8 am), NRS 0-10 was checked again and only IARA patients had another brief appointment with the nurse who followed the preparation.

Third IARA meeting: fourteen day after surgery It is done the same day of the first outpatient orthopedic examination (40 days after surgery). Before starting the patient is given the KOOS and the TSK questionnaire. Subsequently, the overall experience, also regarding possible fears in walking and in daily activities is shared. The recovered motor skills are also verified and, in the event that they are not consistent with the period of the intervention, exercises are recommended to improve the safety of the step. Finally, the creative imagination exercise (Box 2) was repeated.

\section{Measures}

Knee Osteoarthritis Outcome Score (KOOS)

The KOOS 22 assess the patients' opinion about their knee and associated problems. KOOS is meant to be used over both short and long-time intervals; to assess changes from week to week induced by treatment (medication, operation, physical therapy) or over years due to the primary injury or post-traumatic osteoarthritis. KOOS consists of 5 subscales; pain, other symptoms, function in daily living (ADL), function in sport and recreation (Sport/Rec), and quality of life $(\mathrm{QoL})$. The last week is taken into consideration when answering the questions. A normalized score (100 indicating no symptoms and 0 indicating extreme symptoms) was calculated for each subscale.

Tampa Scale Kinesiophobia Questionnaire (TSK) The TSK scale consists of 17 items rated on a fourpoint Likert scale from 0 to 4 (from "strongly disagree", 1; to "strongly agree", 4). Values for the 17 sub-questions were summed to yield a total value, ranging from 17 to 68 . The values for questions 4,8 , 12 , and 16 were reversed before summation. The result of the scale consists of a total score (max 52) and the two scores of the two subscales (TSK $1=$ $\max 24$ and TSK $2=\max 28$ ). The total cut-off of the questionnaire was establish to 37 , the measured margin of error has been estimated as 3 points, then 34 and $40^{23}$. In the Italian version ${ }^{24}$ no cut-off was established at 13 item and it was recommended to consider the total score including all the items which is also considered to be the best solution for the evaluation in the adult age ${ }^{22}$. By carrying out a proportion between the cut-off established by Kori et al. ${ }^{23}$ according to the items ${ }^{24}$ and the acceptable margin of error, we set the cut-off to 31 .

In order to compare the two groups, we then added the scores for the individual subjects and then the score averages in the groups.

NRS $0-10$

After the surgical procedure between $8 \mathrm{pm}$ and $8 \mathrm{am}$, individual pain sensations were detected in both groups through the NRS $0-10$. This scale is based on the use of a scale of 11 degrees (0-10) and identifies "0" the total absence of pain and " 10 " the worst pain imaginable by the patient. The patient is then asked to give his/her pain an intensity score ranging from 0 to 10 .

\section{Ethics approval and consent to participate}

Written consent for participation in this research was obtained from all subjects after being thoroughly in- 
Box 1. Guided imagery performed before surgery

We put ourselves comfortably seated, we draw attention within us through the breath, we connect with the rhythm of our breath, without accelerating or slowing it down.

Now through the breath we imagine bringing in us a breath of fresh air, harmonious, loving, bright and with the air coming out let us go all that is no longer useful at this time.

Through the breath we contact our physical body, bringing the bright and loving air to the bottom of our body by contacting our feet, legs, and pelvis, and imagine that our cells feed on this fresh, bright and loving air and they get rid of what they have accumulated.

With the air coming out we also let go of everything that is no longer useful now.

Gradually up to the abdomen, the chest with its organs, shoulders, arms and hands, and imagine that our cells feed on fresh, bright and loving air and get rid of what they have accumulated.

With the air coming out let us go all that is no longer useful now.

We continue with our breath to contact our neck and face with all senses, the head with inside our mind, our brain, and imagine that our cells feed on fresh, bright and loving air and can get rid of what they have accumulated and with the air coming out let us go all that is no longer useful now.

Now with our breath we contact our emotional level, imagining a calm, clear lake reflecting the surrounding landscape illuminated by a radiant sun.

Let's imagine that a breath of fresh and loving fresh air smoothes our emotions and we imagine that with the air coming out we release all those emotions that are no longer useful now.

Now, always with the breath, let's contact our mental level, imagining a room with closed windows.

Let's imagine opening the windows and making a bright and loving air flowing through our thoughts.

From the windows we can see the air release from those thoughts that are no longer useful now, creating a new space that allows us to catch new thoughts and new insights.

We keep breathing.

Now with the breath we stand in the centre of our heart, where we imagine lighting a light, imagining a lighthouse, a lamp, a stack that we head to the body area that is currently asking for help. Let's see the part of the knee illuminate.

Now we imagine moving from the centre of the hearts some little men that, in the group, with joyful, serene, cooperative attitude, start along the enlightened path.

We see these little men subdivided into subgroups and distributed: a group in the skin to prepare the part to the next scar, another group in the tendons and muscles to favour the opening and another reaches the knee by beginning to activate it to operate it.

Right now we can let go of everything we want to free ourselves.

The little men continue and another group deals with the femur by preparing it for insertion of the prosthesis. Let's have a few moments of listening and watch what's happening, how do men work, if there are pictures, feelings, thoughts, colours, insights that are useful to us for this particular moment. We continue to breathe by giving a bright and loving air that facilitates work and with the air coming out we let go of all that we can still meet but which is no longer useful now.

When we see that they have completed this task, where we see the prosthesis inserted, we can observe the little men that help to close the various muscles, tendons and skin layers.

Always breathing, we see them retreat and always move toward the center of the heart by recompatting the initial group with a joyful, cooperative and compassionate attitude.

Now through the breath we imagine spreading a quality: gratitude. And we do it at all our levels: physical, emotional and mental. For the experience that we have experienced and taken care of.

Now, with the air coming out we let go of what's still present and it's no longer useful now.

We pay attention to here and now, to our body and, always keeping in touch with the breath, we start to move our feet, legs, hands, shoulders.

Now, when we are ready, we re-open our eyes and get back into contact with the outside world.

formed (both oral and written information) about the purpose of this study before surgery. This study was approved by local Ethics Committee and this investigation was performed in conformity with the Code of Ethics of the World Medical Association (Declaration of Helsinki) and meets the ethical standards of the MLTJ25.

\section{Data analysis}

Two-way mixed design between-within $2 \times 2$ ANOVA was used in order to detect differences between control and experimental groups (factor Group) on changes in the psychological factors before and after the intervention (factor Time). For those variables in which interaction Time $\times$ Group was significant, one- 
Box 2. Guided imagery performed after $40^{\text {th }}$ days from surgery

We put ourselves comfortably seated, we draw attention within us through the breath, we connect with the rhythm of our breath, without accelerating or slowing it down.

Now through the breath we imagine bringing in us a breath of fresh air, harmonious, loving, bright and with the air coming out let us go all that is no longer useful at this time.

Through the breath we contact our physical body, bringing the bright and loving air to the bottom of our body by contacting our feet, legs, and pelvis, and imagine that our cells feed on this fresh, bright and loving air and they get rid of what they have accumulated.

With the air coming out we also let go of everything that is no longer useful now.

Always breath gradually up to the abdomen, the chest with its organs, shoulders, arms and hands, and imagine that our cells feed on fresh, bright and loving air and get rid of what they have accumulated.

With the air coming out let us go all that is no longer useful now.

We continue with our breath to contact our neck and face with all senses, the head with inside our mind, our brain, and imagine that our cells feed on fresh, bright and loving air and can get rid of what they have accumulated and with the air coming out let us go all that is no longer useful now.

Now with our breath we contact our emotional level, imagining a calm, clear lake reflecting the surrounding landscape illuminated by a radiant sun.

Let's imagine that a breath of fresh and loving fresh air smoothes our emotions and we imagine that with the air coming out we release all those emotions that are no longer useful now.

Now, always with the breath, let's contact our mental level, imagining a room with closed windows.

Let's imagine opening the windows and making a bright and loving air flowing through our thoughts.

From the windows we can see the air release from those thoughts that are no longer useful now, creating a new space that allows us to catch new thoughts and new insights.

We keep breathing.

Now with the breath we stand in the centre of our heart, where we imagine lighting a light, imagining a lighthouse, a lamp, a stack that we head to the body area that is currently asking for help. We see the knee part of the prosthesis illuminated.

Now we imagine moving from the centre of the hearts some little men that in the group, with joyful, serene, cooperative attitudes start along. Let's imagine looking at the various little men subdivided into subgroups, which are concerned with maintaining the equilibrium and harmony of the knee by seeing the functioning and aligned prosthesis. Let's have a few moments of listening and see what's happening, what do men do, how to care for the part played, and if there are images, feelings, thoughts, colours, intuitions that are useful to us for this particular moment.

We continue to breathe by inserting a bright and loving air that facilitates the care work and with the air coming out we let go of everything we can still meet but which is no longer useful now.

Always breathing, we see them retreat and always move toward the centre of the heart by recompatting the initial group with a joyful, cooperative and compassionate attitude.

Now through the breath we imagine spreading a quality: gratitude.

And we do it at all our levels: physical, emotional and mental.

For the experience that we have experienced and taken care of.

Now, with the air coming out we let go of what is still present and it is no longer useful now.

We pay attention to here and now, to our body and, always keeping in touch with the breath, we start moving our feet, legs, hands and shoulders.

Now, when we are ready, we reopen our eyes and get back into contact with the outside world.

way repeated measures ANOVA was performed to analyze the simple main effect among three-time points in each group. ANOVA is robust to small and even moderate violations of its assumptions, meaning that the probability values $(p<0.001)$ computed are sufficiently accurate even if the assumptions are violated. Analysis of covariance (ANCOVA) was applied on those variables in which time and group had interaction effects using the pretest data as the covariate to align the group differences at baseline of the initial measurement point with the aim of assessing the group differences at the end of the study. Effect sizes are presented as partial eta-squared $\left(\eta^{2} p\right)$ to deter- mine the meaningfulness of the results. As suggested by Cohen ${ }^{26}$, threshold values to effect size were 0.01 (small), 0.06 (medium), and 0.14 (large). A $p$ value of less than 0.05 was regarded as a statistically significant difference. Statistical analyses were carried out using Statistica software version 13.0 (Dell Inc., Round Rock, TX USA).

\section{Results}

A total of 84 patients out of entire cohort $(n=100)$ available during the period of recruitment completed 
the quasi-experiment trial. Six patients refused to participate in the study, and 10 were excluded or failed to fill out questionnaires.

Results of $t$ test at baseline of the research showed that there was significant difference in Pain $(t=2.092$, $\mathrm{p}=0.040)$ and Symptom $(\mathrm{t}=2.123, \mathrm{p}=0.037)$ between observed groups. With applied two-way mixed design ANOVA, we found significant Time $\times$ Group interaction in all KOOS subscales (Tab. I): Pain $\left(F_{1,82=10.808 \text {, }}\right.$ $\mathrm{p}<0.001)$; Symptom $\left(F_{1,82}=15.497, p<0.001\right)$; ADL $\left(F_{1,82}=20.342, p<0.001\right)$; Sport $/ \operatorname{Rec}\left(F_{1,82}=20.451\right.$,

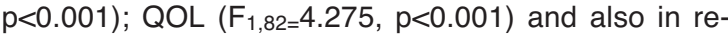
gard to TSK questionnaire $\left(F_{1,82}=4.275, p=0.042\right)$.

Table II shows simple main effect of different time points in each group. In IARA group we found significant decrease in mean scores in all KOOS subscales: Pain $\left(F_{1,43}=178.093, p<0.001\right)$; Symptom $\left(F_{1,43}=75.793, \quad p<0.001\right) ; \quad A D L \quad\left(F_{1,43}=219.288\right.$, $\mathrm{p}<0.001)$; Sport/Rec $\left(\mathrm{F}_{1,43}=223.283, \mathrm{p}<0.001\right)$; $\mathrm{QoL}$ $\left(F_{1,43}=171.389, p<0.001\right)$. Same decrease was found in control group: Pain $\left(F_{1,39}=178.093, p<0.001\right)$; Symptom $\left(F_{1}, 39=75.793, p=0.033\right)$; ADL $\left(F_{1}\right.$, $39=219.288, p<0.001)$; Sport $/ \operatorname{Rec}\left(F_{1}, 39=223.283\right.$,

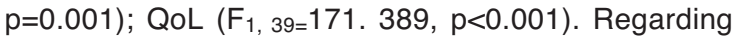
TSK questionnaire we found that there was no significant decrease in IARA and control group

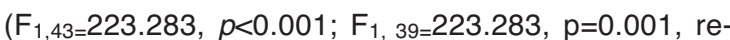
spectively). However, there was medium (IARA: $\eta^{2}=0.083$ ) and small (Control: $\eta^{2}=0.083$ ) effect size in observed groups.

Group differences are show in Table III. We found significantly difference in all variables: Pain $\left(F_{1,81}=10.808, p=0.012\right)$; Symptom $\left(F_{1,81}=13.715\right.$, $\mathrm{p}<0.001)$; ADL $\left(\mathrm{F}_{1,81}=15.385, \mathrm{p}<0.001\right)$; Sport/Rec $\left(F_{1,81}=23.841, p<0.001\right)$; QoL $\left(F_{1,81}=19.071, p<0.001\right)$ and also in regard to TSK $\left(F_{1,81}=20.924, p=0.042\right)$. By observing the mean scores, IARA group benefit more from the intervention (in all variables mean was lower than control group).

The pain reported by subjects (Fig. 2) in the first postoperative evaluation $(8 \mathrm{pm})$ was particularly low given the effect of anesthesia in two groups (IARA: 1.55 \pm 0.93 ; Control: $1.60 \pm 0.90$ ). The pain reported by subjects at $8 \mathrm{pm}$ was slightly lower in the IARA group $(1.16 \pm 0.90)$ than in the control group $(1.30 \pm 1.04)$.

\section{Discussion}

We have demonstrated the effectiveness of model IARA in improving indexes of kinesiophobia, pain and quality of life in patients undergoing TKA.

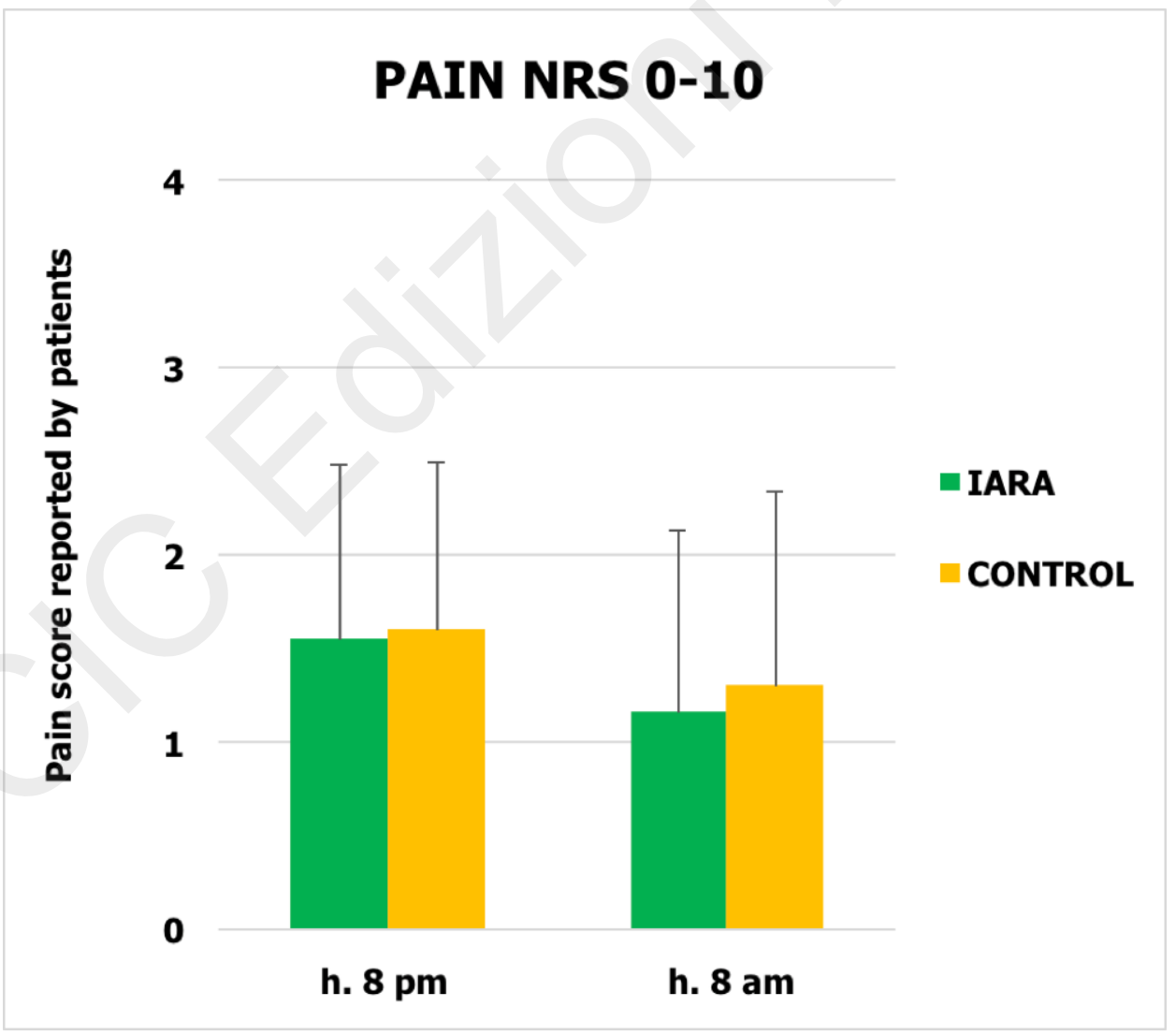

Figure 2. The graph represents the pain mean and standard deviation reported at NRS $0-10$ by groups at $8.00 \mathrm{pm}$ (first detection for all patients) and $8.00 \mathrm{am}$ (second detection for all patients). 
The surgical part, although performed by different orthopedics, can be considered effective as the improvement of the pre- and post-intervention control group has been highly significant (Tab. I). Many researchers have shown increasing interest in pain management in the immediate postoperative and described how $50 \%$ of people undergoing arthroplasty report pain as major concern ${ }^{3,27}$.

The pharmacological strategy of pain control in the immediate post-surgical treatment has been shown to be effective because of the pain reported by patients (Fig. 2).

Alongside the pain the fear of movement has been described as an extremely important problem since it can affect postoperative hospitalization ${ }^{28}$.

Kinesiophobia can induce the patient to hypervigilance towards bodily sensations (feel, pressure, movement, etc.), which can even lead to idleness, depression and disability ${ }^{29}$. In turn, this hyper vigilance can feed into a vicious cycle that amplifies both cognitive/psychological components (pain catastrophizing, anxiety, depression) and behavioral components (kinesiophobia) leading to general dissatisfaction with the inserted prosthesis ${ }^{30}$ : intervention on these components is therefore crucial in improving the outcome in patients undergoing TKA in the short and long term.

Monticone et al. ${ }^{31}$ have proposed to include a kinesiophobia management program that encourages patients to think differently about how they cope with the pain, leading to new patterns of behavior. The proposed programs result in a perception of lower pain and disability. Monticone et al. ${ }^{31}$ applied their approach to the management of kinesiophobia in a randomized experiment demonstrating a decrease in kinesiophobia greater than 14 points in the experimental group and about 2 points in the control group.
The Authors have also shown a significant reduction in pain, and a better quality of life. However, the authors performed their experiment-recruiting patients at the end of a 15-day period of in-hospital rehabilitation after undergoing primary TKA.

In this study we tried to maintain lower levels of kinesiophobia during the entire perioperative period asking to patients to get involved in the care process and we can infer that lowest mean values of kinesiphobia in the sperimental group were due to IARA intervention (Tabs. I-III).

Exploration of the influence of psychological factors in the preoperative period has already been demonstrated in lumbar spinal fusion surgery patients ${ }^{32}$ and in patients with lumbar stenosis and / or herniated $\operatorname{disc}^{33}$, where authors have highlighted how psychological factors mediate and play a central role in pain, kinesiophobia, re-injury and disability.

Furthermore, Sullivan et al. ${ }^{34}$ have highlighted how psychological factors (catastrophism, kinesiophobia, depression) are confounded by patients and are decisive about expectations prior to surgery (i.e., when the patient plans to resume normal family, social and recreational activities) that affect functional recovery after TKA. Sánchez-Herán et al. ${ }^{35}$ studied the relationship of fear-avoidance beliefs and pain catastrophizing with postural stability in subjects with hip and knee osteoarthritis, giving further demonstration that psychosocial factors should be taken into consideration in the assessment and treatment of these patients.

Having checked kinesiophobia the day before the operation led us to find that the control group was approaching the operation differently and this aspect reverberated until the first post-surgical visit.

The data are also consistent with the KOOS questionnaire, where scores in all subscales are signifi-

Table I. Results of two way repeated measures ANOVA within/between subjects effects and interaction.

\begin{tabular}{|c|c|c|c|c|c|c|c|}
\hline & \multirow{2}{*}{ Variable } & \multicolumn{2}{|c|}{ Time } & \multicolumn{2}{|c|}{ Group } & \multicolumn{2}{|c|}{ TimexGroup } \\
\hline & & $F(p)$ & $\eta^{2}$ & $F(p)$ & $\eta^{2}$ & $F(p)$ & $\eta^{2}$ \\
\hline & Pain & $\begin{array}{c}177.219 \\
(0.000)^{\star \star \star}\end{array}$ & 0.684 & $0.036(0.850)$ & 0.000 & $\begin{array}{c}10.808 \\
(0.000)^{\star *}\end{array}$ & 0.116 \\
\hline & Symptom & $\begin{array}{c}53.874 \\
(0.000)^{\star \star \star}\end{array}$ & 0.397 & $0.373(0.0 .543)$ & 0.005 & $\underset{\star \star \star \star}{15.497(0.000)}$ & 0.159 \\
\hline \multirow[t]{4}{*}{ koOs } & $A D L$ & $\begin{array}{c}22.091 \\
(0.000)^{\star \star \star}\end{array}$ & 0.212 & $3.334(0.072)$ & 0.039 & $\begin{array}{c}20.342 \\
(0.000)^{\star \star \star}\end{array}$ & 0.199 \\
\hline & Sport/Rec & $\begin{array}{c}114.177 \\
(0.000)^{\star \star \star}\end{array}$ & 0.582 & $\begin{array}{c}10.516 \\
(0.002)^{\star \star}\end{array}$ & 0.114 & $\begin{array}{c}20.451 \\
(0.000)^{\star \star \star}\end{array}$ & 0.200 \\
\hline & QOL & $\begin{array}{c}137.128 \\
(0.000)^{\star \star \star}\end{array}$ & 0.626 & $7.062(0.009)$ & 0.079 & $\begin{array}{c}18.347 \\
(0.000)^{\star \star \star}\end{array}$ & 0.183 \\
\hline & TSK & $1.354(0.248)$ & 0.016 & $20.992(0.000)$ & 0.204 & $4.275(0.042)^{\star}$ & 0.050 \\
\hline
\end{tabular}

Legend: $F$, $f$ test; $p$, significance; $\eta^{2}$, effect size; ${ }^{*} p<0.05 ;{ }^{* *} p<0.01 ;{ }^{* \star *} p<0.001$ 
Table II. Differences among pre- and post-testing (timex group significant interaction effect).

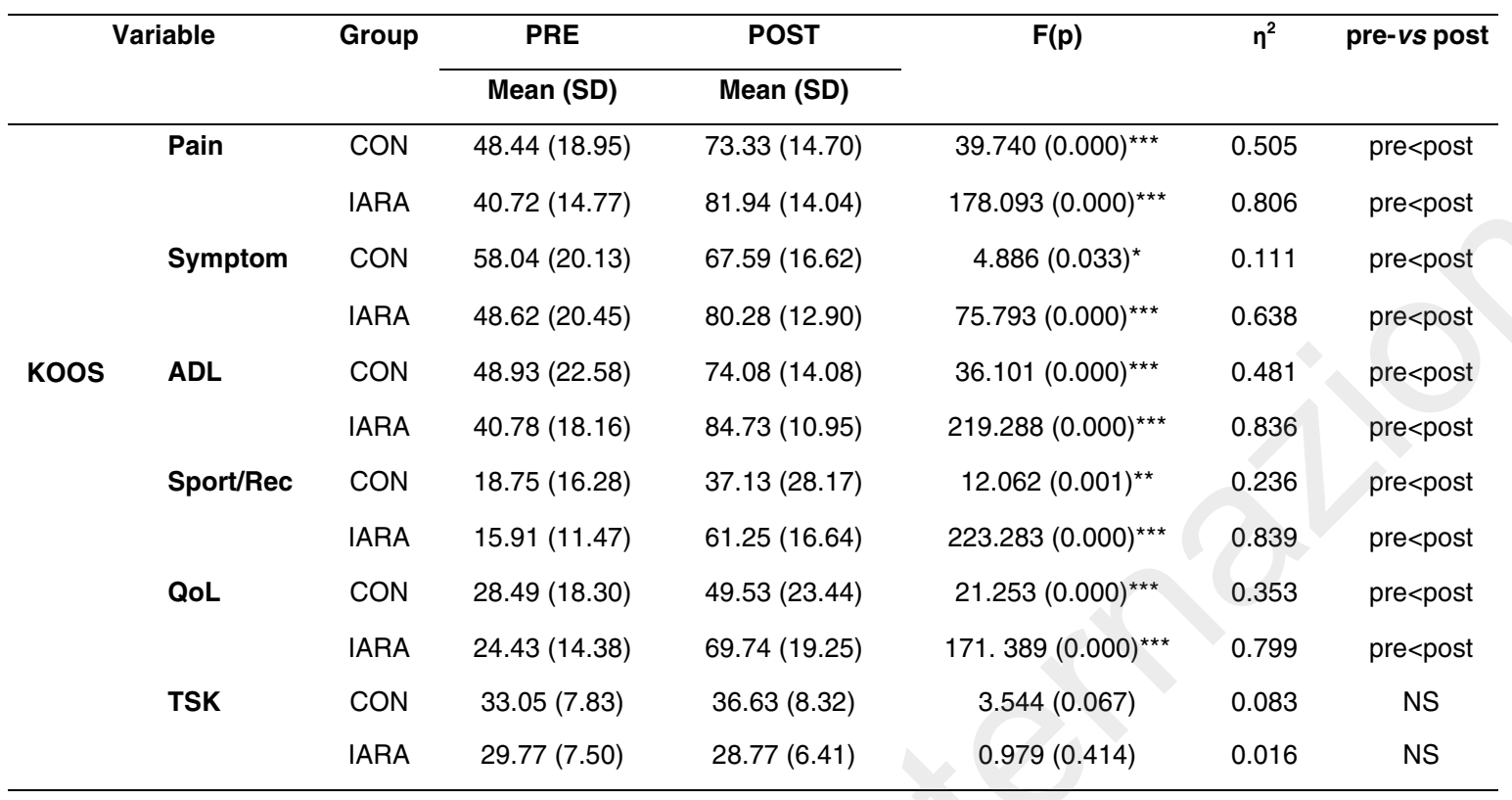

Legend: $F$, f test; $p$, significance; NS, non significant; ${ }^{*} p<0.05 ;{ }^{* *} p<0.01 ;{ }^{* * *} p<0.001$

Table III. Post-intervention differences between group (timexgroup significant interaction effect).

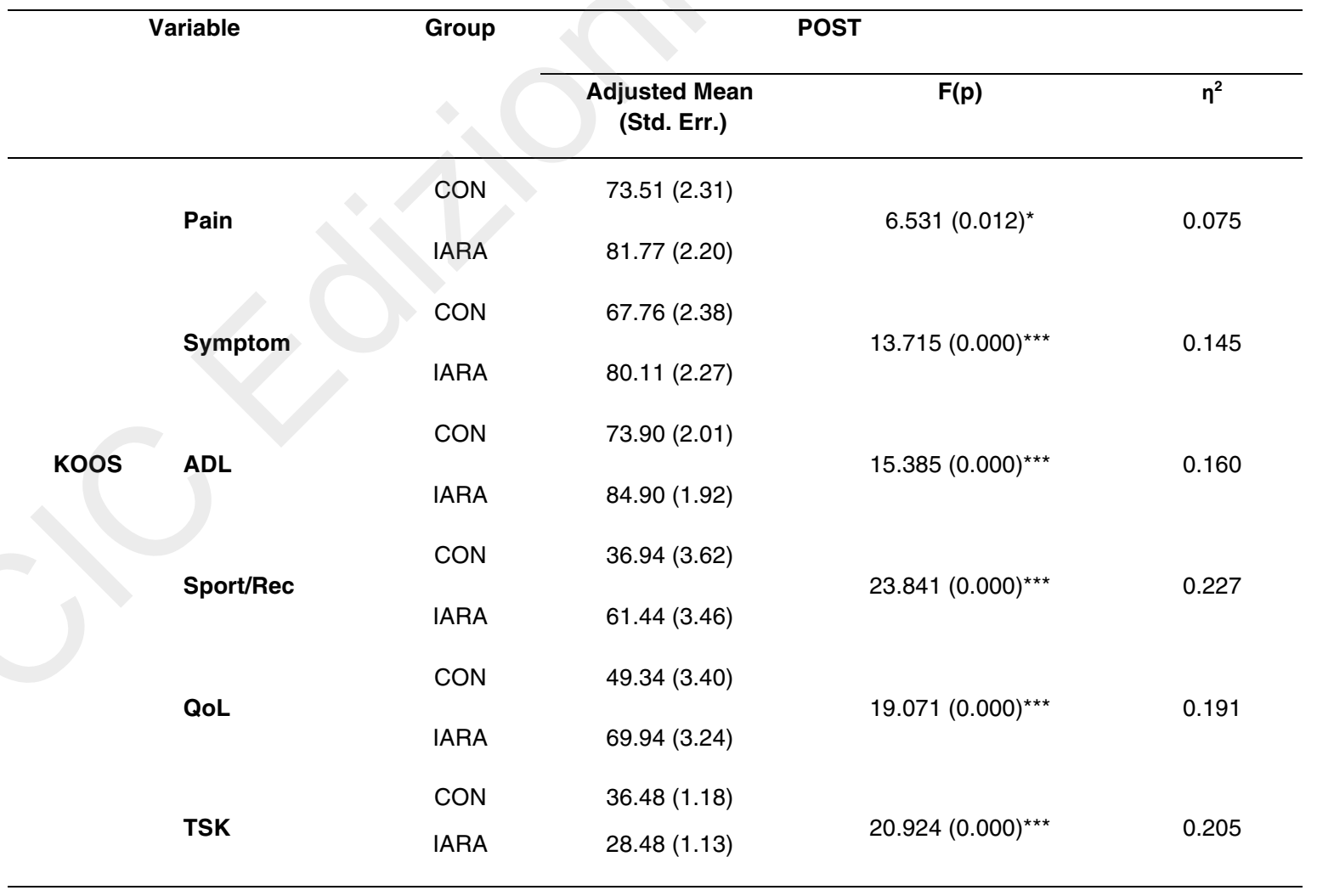

Legend: F, f test; $p$, significance; ${ }^{*} p<0.05 ;{ }^{* *} p<0.01 ;{ }^{* * *} p<0.001$ 
cantly better in IARA group compared to the control group.

The fact that patients had been prepared for surgical examination in every aspect, also by preoperative home and postoperative exercises he/she would have done in the clinic, and describing what the physiotherapist would have done in the days later the intervention, may have contributed to improving psychological aspects which, in turn, diminished kinesiophobia by increasing the overall quality of life of patients verified at $40^{\text {th }}$ day postoperative.

Accompanying the person in the perioperative path is decisive in making him/her more serene and aware, as it is decisive that the various health professionals interact to keep the person in the middle on his/her path by implementing a personalized assistance.

In fact, the literature has shown how the collaboration process between the various health figures is decisive for the well-being of the patient and how this process leads him to be the protagonist of his care pathway ${ }^{11}$. Therefore, IARA could facilitate the patient's empowerment because he/she finds answers to his/her doubts, uncertainties and expectations, encouraging his/her collaboration with healthcare professionals and his/her active participation during the perioperative course.

Through the IARA model, it was possible to increase the awareness of the health personnel about the usefulness and effectiveness of the use of custom music (i.e., patient choice) during surgery and throughout the peri- operative period. The use of this personcentered resource has two advantages: the first is that the music chosen by the person favors a state of psychic well-being ${ }^{36}$; the second is due to the fact that during the surgery the person is able to shift his/her attention from the noises of a orthopedic operating theater to music, living an experience that is reported as non-traumatic.

Further studies are necessary to show the full effectiveness of the IARA in TKA surgical preparation, but the results of these cases are extremely encouraging.

\section{Limitation of the study}

A quasi-experimental procedure was utilized to carry out this study in which patients in an intervention group and patients in a control group, who were given the same care, were consecutively compared. This design mainly intended avoiding working with two care systems at the same time. Furthermore, no power analysis was performed a priori and this procedure may preclude from evaluating the real effects of an intervention. Actually, it is not possible to infer whether the differences between the two groups are the results of the intervention rather than due to unknown factors. Consequently, the conclusions of this study should be made with caution, considering that non-randomized experimental designs, under particular circumstances, cannot provide accurate data.

It is important to point out that both control and inter- vention groups were recruited according to the same protocol although random assignment had not been applied.

All the healthcare professionals involved in this experimental procedure regularly met to be constantly informed about the important decisions or changes that could positively or negatively influence this study. Due to summer and winter closing recruitment was stopped for a few weeks.

However, this does not seem to have affected any of the measured variables.

Finally, it is necessary to consider that this study uses a highly specific method which requires specific nurse training. For this reason, it could lead to further costs to public hospitals. The evaluation of costs of the IARA Method in hospitals could be a point for further research activities.

\section{References}

34. Sullivan M, Tanzer M, Reardon G, Amirault D, Dunbar M, Stan- ish W. The role of presurgical expectancies in predicting pain and function one year following total knee arthroplasty. Pain. 2011;152:2287-2293.

1. Hawker G, Wright J, Coyte $P$, et al. Health-related quality of life after knee replacement. J Bone Joint Surg Am. 1998;80 (2):163-173.

2. Wylde V, Dieppe P, Hewlett S, Learmonth ID. Total knee replacement: Is it really an effective procedure for all? Knee. 2007;14(6):417-423.

3. Lewis GN, Rice DA, McNair PJ, Kluger M. Predictors of persistent pain after total knee arthroplasty: a systematic review and meta-analysis. Br J Anaesth. 2015;114(4):551-561 .

4. Paterson KL, Sosdian L, Hinman RS, et al. The influence of sex and obesity on gait biomechanics in people with severe knee osteoarthritis scheduled for arthroplasty. Clin Biomech (Bristol, Avon). 2017;49:72-77. Doi: 10.1016/j.clinbiomech. 2017.08.013.

5. Hirakawa Y, Hara M, Fujiwara A, Hanada H, Morioka S. The relationship among psychological factors, neglect-like symptoms and postoperative pain after total knee arthroplasty. Pain Res Manag. 2014;19(5):251-256.

6. Leeuw M, Goossens ME, Linton SJ, Crombez G, Boersma K, Vlaeyen JW. The fear-avoidance model of musculo-skeletal pain: current state of scientific evidence. J Behav Med. 2007;30(1):77-94.

7. van Wilgen CP, Dijkstra PU, Versteegen GJ, Fleuren MJ, Stewart R, van Wijhe M. Chronic pain and severe disuse syndrome: long-term outcome of an inpatient multidisciplinary cognitive behavioural programme. J Rehabil Med. 2009;41(3): 122-8. Doi: 10.2340/16501977-0292.

8. Filardo G, Roffi A, Merli G, et al. Patient kinesiophobia affects both recovery time and final outcome after total knee arthroplasty. Knee Surg Sports Traumatol Arthrosc. 2016;24(10): 3322-3328.

9. De Giorgio A. From emotional education to collaborative intelligence. Espressivamente. 2016. ISSN: 2239-4044.

10. Martin LR, Williams SL, Haskard KB, Dimatteo MR. The challenge of patient adherence. Ther Clin Risk Manag. 2005. PMCID: PMC1661624.

11. Epstein RM, Street RL Jr. The values and value of patient-centered care. Ann Fam Med. 2011;9(2):100-3. Doi: 10.1370/afm. 1239.

12. Bourne RB, McCalden RW, MacDonald SJ, Mokete L, Guerin J. Influence of patient factors on TKA outcomes at 5 to 11 
years follow-up. Clin Orthop Relat Res. 2007;464:27-31.

13. Gulotta F, Grazzi L, Allais GB, et al. P031. An observational study on chronic tension-type headache treatment with Quantum Molecular Resonance according to I.A.R.A. model®. J Headache Pain. 2015 Dec;16(Suppl 1):A176. Doi: 10.1186/ 1129-2377-16-S1-A176.

14. De Giorgio A, Dante A, Cavioni V, et al. The IARA Model as an integrative approach to promote autonomy in COPD patients through improvement of self-efficacy beliefs and illness perception: A mixed-method pilot study. Front Psychol. 2017. Doi: 10.3389/fpsyg.2017.01682.

15. De Giorgio A, Loscalzo RM, Ponte M, Padovan AM, Graceffa G, Gulotta F. An innovative mindfulness and educational care approach in an adult patient affected by gastroesophageal reIux: the IARA model. Complement Integr Med. 2016. Doi:10.1515/jcim-0154.

16. Assagioli R. Psychosynthesis. A Manual of Principles and Techniques, New York, N.Y., The Viking Press, 1965.

17. Buza JA, Fink LA, Levine WN. Sports activity after total joint arthroplasty: recommendations for the counseling physician. Phys Sportsmed. 2013;41:9-21. Doi:10.3810/psm. 2013.02. 1994.

18. Maddison R, Prapavessis H, Clatworthy M, et al. Guided imagery to improve functional outcomes post-anterior cruciate ligament repair: randomized-controlled pilot trial. Scand J Med Sci Sports. 2012;22:816-21. Doi: 10.1111/j.1600-0838.2011. 01325.x

19. Grazzi L, Sansone E, Raggi A, D'Amico D, De Giorgio A, Leonardi M, De Torres L, Salgado-García F, Andrasik F. Mindfulness and pharmacological prophylaxis after withdrawal from medication overuse in patients with Chronic Migraine: an effectiveness trial with a one-year follow-up. J Headache Pain. 2017;18:15. Doi: 10.1186/s10194-017-0728-z.

20. Huang TT, Sung CC, Wang WS, Wang BH. The effects of the empowerment education program in older adults with total hip replacement surgery. J Adv Nurs. 2017;73:1848-1861. Doi: 10.1111/jan.13267.

21. Kuvacic G, Fratini P, Padulo J, Dello lacono A, De Giorgio A. Effectiveness of yoga and educational intervention on disability, anxiety, depression, and pain in people with CLBP: A randomized controlled trial. Complement Ther Clin Pract. 2018; 31:262-267. DOI: 10.1016/j.ctcp.2018.03.008.

22. Roos EM, Lohmander LS. The Knee injury and Osteoarthritis Outcome Score (KOOS): from joint injury to osteoarthritis. Health and Quality of Life Outcomes. 2003;1:64. Doi: 10.1186/ 1477-7525-1-64.

23. Kori SH, Miller RP, Todd DD. Kinesiophobia: a new view of chronic pain behavior. Pain Manage. 1990;3:35-43.
24. Monticone M, Giorgi I, Baiardi P, BarbieriM, RoccaB, Bonezzi C. Development of the Italian version of the Tampa Scale of Kinesiophobia (TSK-I): cross-cultural adaptation, factor analysis, reliability, and validity. Spine (Phila Pa 1976). 2010;35: 1241-1216. Doi: 10.1097/BRS.0b013e3181bfcbf6.

25. Padulo J, Oliva F, Frizziero A, Maffulli N. Muscles, Ligaments and Tendons Journal - Basic principles and recommendations in clinical and field Science Research: 2016;Update. MLTJ. 2016;6(1):1.

26. Cohen J. Statistical power analysis for the behavioral sciences. (2nd ed.) Hillsdale, NJ Erlbaum 1988.

27. Castorina S, Guglielmino C, Castrogiovanni P, et al. Clinical evidence of traditional vs fast track recovery methodologies after total arthroplasty for osteoarthritic knee treatment. A retrospective observational study. Muscles Ligaments Tendons J. 2018;10;7(3):504-513. DOI: 10.11138/mltj/2017.7.3.504.

28. Doury-Panchout F, Metivier JC, Fouquet B. Kinesiophobia negatively influences recovery of joint function following total knee arthroplasty. Eur J Phys Rehabil Med. 2015;51:155-161.

29. Vlaeyen JW, Linton SJ. Fear-avoidance and its consequences in chronic musculoskeletal pain: a state of the art. Pain. 2000;85:317-32.

30. Choi YJ, Ra HJ. Patient Satisfaction after Total Knee Arthroplasty. Knee Surg Relat Res. 2016 Mar;28(1):1-15. Doi 10.5792/ksrr.2016.28.1.1.

31. Monticone M, Ferrante S, Rocca B, et al. Home-based functional exercises aimed at managing kinesiophobia contribute to improving disability and quality of life of patients undergoing total knee arthroplasty: a randomized controlled trial. Arch Phys Med Rehabil. 2013;94(2):231-239.

32. Abbott AD, Tyni-Lenné R, Hedlund R. The influence of psychological factors on preoperative levels of pain intensity, disability and health-related quality of life in lumbar spinal fusion surgery patients. Physiotherapy. 2010;96(3):213-221 . Doi:10.1016/j.physio.2009.11.013.

33. van Wilgen CP, Stewart R, Patrick Stegeman PT, Coppes M, van Wijhe M. Fear of movement in preoperative patients with a lumbar stenosis and or herniated disc: factor structure of the Tampa scale for kinesiophobia. Man Ther. 2010;15(6):593598. Doi: 10.1016/. .math.2010.07.002.

35. Sánchez-Herán Á, Agudo-Carmona D, Ferrer-Peña R, et al. Postural Stability in Osteoarthritis of the Knee and Hip: Analysis of Association With Pain Catastrophizing and Fear-Avoidance Beliefs. PM R. 2016;8:618-628. Doi: 10.1016/j.pmrj.2015.11.002.

36. Zatorre RJ, Salimpoor VN. From perception to pleasure: music and its neural substrates. Proc Natl Acad Sci U S A. 2013;18 110(Suppl 2):10430-10437. Doi:10.1073/pnas. 1301228110. 